\title{
Most Severe Acute Stressor
}

National Cancer Institute

\section{Source}

National Cancer Institute. Most Severe Acute Stressor. NCI Thesaurus. Code C124437.

The agent, stimulus, activity, or event that causes stress with an acute frequency, which has the highest level of severity. 